\title{
Assessing small airways dysfunction in asthma, asthma remission and healthy controls using particles in exhaled air
}

\author{
To the Editor:
}

Asthma is a chronic disease, characterised by variable airflow obstruction and airway inflammation [1]. Small airways are thought to be a major site of pathology in asthma $[2,3]$. There are different tools to assess small airways dysfunction (SAD), such as spirometry, body plethysmography, impulse oscillometry (IOS), multiple-breath nitrogen washout $(\mathrm{MBNW})$, alveolar fraction of exhaled nitric oxide $\left(F_{\mathrm{ENO}}\right)$ and gas trapping assessed by high-resolution computed tomography (CT). However, there is no golden standard and some tests are difficult to perform [2,3]. Particles in exhaled air (PExA) is a recently developed technique with the potential to identify SAD phenotypes in asthma $[4,5]$. PExA measurements are noninvasive and easy for subjects to perform, even in severely obstructed patients. PExA captures the aerosol from exhaled breath, and specifically those endogenously generated particles in the size range $0.5-4 \mu \mathrm{m}$ that are formed during airway closure and reopening. These particles contain water and nonvolatile material originating from the respiratory tract lining fluid [6]. It is thought that SAD leads to impaired reopening of airways or altered composition of the respiratory tract lining fluid, causing fewer particles to be formed [7]. Therefore, severity of SAD is expected to be associated with a reduction of particles measured by PExA.

Some patients with asthma outgrow their disease and reach clinical asthma remission (ClinR); these individuals experience no asthma symptoms even without using asthma medication. Patients in ClinR, however, might still have (asymptomatic) bronchial hyperresponsiveness (BHR) or impaired lung function [8-10]. Broekema et al. [11] demonstrated that subjects in ClinR still had ongoing airway inflammation. In contrast, a smaller subset of asthma remission subjects may lack BHR and regain normal lung function, i.e. complete asthma remission (ComR) [10].

We hypothesised that more SAD leads to decreased exhalation of PExA particles and that this SAD is still present in ClinR but absent in ComR subjects. Therefore, we compared exhaled PExA mass between ClinR and ComR subjects in relation to asthma patients and healthy controls. The second aim of this study was to investigate how PExA mass is associated with other measures of small and large airways function in these groups.

The study protocol was approved by the local ethical committee and all subjects gave informed consent (NL53173.042.15; Groningen, the Netherlands). The included subjects were divided over four groups: the first three groups were subjects with childhood-onset asthma that 1) persisted (PersA; subjects with wheezing and/or asthma attacks, asthma medication use, and a provocative concentration causing a $20 \%$ fall in forced expiratory volume in $1 \mathrm{~s}\left(\mathrm{PC}_{20}\right)$ for methacholine of $<8 \mathrm{mg} \cdot \mathrm{mL}^{-1}$ with $120 \mathrm{~s}$ tidal breathing), or that 2) had gone into clinical asthma remission (ClinR; subjects without wheezing/asthma attacks, no use of asthma medication in the last 3 years, with a documented history of asthma according to Global Initiative for Asthma guidelines, a forced expiratory volume in $1 \mathrm{~s}\left(\mathrm{FEV}_{1}\right)<80 \%$ predicted and/or $\mathrm{PC}_{20}$ methacholine $<8 \mathrm{mg} \cdot \mathrm{mL}^{-1}$ ), or 3 ) into complete asthma remission (ComR; similar to ClinR, but with an $\mathrm{FEV}_{1} \geqslant 80 \%$ pred, $\mathrm{PC}_{20}$ methacholine $\geqslant 8 \mathrm{mg} \cdot \mathrm{mL}^{-1}$ and $\mathrm{PC}_{20} \mathrm{AMP} \geqslant 320 \mathrm{mg} \cdot \mathrm{mL}^{-1}$ ); the fourth group was healthy controls (Ctrl; similar to ComR, but without any history of asthma or use of asthma medication).

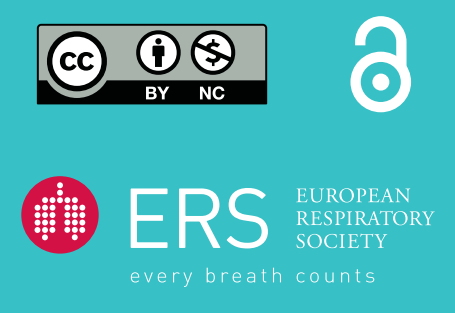

@ERSpublications

PExA mass can distinguish asthmatics from healthy individuals. Subjects with complete, but not clinical, asthma remission exhale more PExA mass compared to asthma. Higher PExA mass was associated with better function of both the small and large airways. http://bit.ly/2znHABg

Cite this article as: Carpaij OA, Muiser S, Bell AJ, et al. Assessing small airways dysfunction in asthma, asthma remission and healthy controls using particles in exhaled air. ERJ Open Res 2019; 5: 00202-2019 [https://doi.org/10.1183/23120541.00202-2019]. 
All subjects were aged 40-65 years and were either never- or ex-smokers with a smoking history $<10$ pack-years. Subjects were extensively characterised with the following tests: spirometry, body plethysmography, IOS, $F_{\mathrm{ENO}}$, MBNW, provocation tests, blood tests, sputum induction and CT scans. PersA subjects were withdrawn from inhaled corticosteroids 6 weeks prior to the clinical characterisation.

PExA mass was collected using the PExA 2.0 device [5]. All subjects performed a similar breathing manoeuvre as described by BAKE et al. [6]. To account for potential bias effects of circadian rhythm, all PExA measurements were performed in the morning.

Parametric response mapping (PRM) is a voxel-wise image analysis technique that was implemented on the CT scans. PRM data were analysed according to the methods described in the literature $[12,13]$.

\begin{tabular}{|c|c|c|c|c|c|}
\hline Characteristics & Ctrl & ComR & ClinR & PersA & $\begin{array}{l}\text { Kruskal-Wallis } \\
\text { p-value }\end{array}$ \\
\hline Subjects $n$ & 18 & 12 & 16 & 18 & \\
\hline Age years & $56(53-61)$ & $46(43-55)$ & $54(47-60)$ & $60(49-63)$ & 0.044 \\
\hline Female & 6 (33.3) & $4(33.3)$ & $7(43.8)$ & $7(38.9)$ & $0.918^{\text {I }}$ \\
\hline $\begin{array}{l}\text { Smoking pack-years median } \\
\text { (min-max) }\end{array}$ & $0(0-5)$ & $0(0-6)$ & $0(0-1)$ & $0(0-2)$ & 0.104 \\
\hline $\mathrm{FEV}_{1} \%$ pred & $113.6 \pm 12.0$ & $108.1 \pm 9.5$ & $84.5 \pm 23.1$ & $81.3 \pm 17.2$ & $<0.001$ \\
\hline $\mathrm{PC}_{20}$ methacholine & $>8$ & $>8$ & $0.8(0.1-2.8)$ & $0.6(0.3-2.2)$ & \\
\hline \multirow[t]{2}{*}{ PExA mass $\mathrm{ng} \cdot \mathrm{L}^{-1}$} & 5.68 & 4.87 & 3.15 & 2.67 & $0.017^{+}$ \\
\hline & (3.01-9.57) & $(2.90-6.45)$ & $(0.71-5.63)$ & (0.49-4.02) & \\
\hline Parameter & Test & R-value & p-value & & \\
\hline Age years & Spearman & 0.095 & 0.455 & & \\
\hline Body mass index $\mathrm{kg} \cdot \mathrm{m}^{-2}$ & Spearman & -0.203 & 0.107 & & \\
\hline \multicolumn{6}{|l|}{ Inflammatory } \\
\hline Blood eosinophils $\times 10^{9}$ cells. $\mathrm{L}^{-1} \#$ & Pearson & -0.182 & 0.154 & & \\
\hline Sputum eosinophil differentiation \% & Spearman & -0.449 & 0.013 & & \\
\hline \multicolumn{6}{|l|}{ Large } \\
\hline Reversibility pre-post \% & Spearman & -0.469 & $<0.001$ & & \\
\hline $\begin{array}{l}\mathrm{PC}_{20} \text { methacholine slope } \\
\mathrm{mg} \cdot \mathrm{mL}^{-1 \#}\end{array}$ & Pearson & -0.483 & $<0.001$ & & \\
\hline $\mathrm{PC}_{20}$ AMP slope $\mathrm{mg} \cdot \mathrm{mL}^{-1}$ & Spearman & -0.441 & 0.001 & & \\
\hline $\mathrm{FEV}_{1} / \mathrm{FVC}$ ratio pre-salbutamol $\%$ & Spearman & 0.355 & 0.004 & & \\
\hline $\mathrm{FEV}_{1} \%$ pred pre-salbutamol & Pearson & 0.417 & 0.001 & & \\
\hline $10 \mathrm{~S} R_{20} \mathrm{~Hz}$ & Pearson & -0.386 & 0.002 & & \\
\hline \multicolumn{6}{|l|}{ Small } \\
\hline $10 \mathrm{~S} R_{5}-R_{20} \mathrm{~Hz}$ & Spearman & -0.308 & 0.014 & & \\
\hline IOS AX Hz:kPa. $\mathrm{L}^{-1}$ & Spearman & -0.342 & 0.006 & & \\
\hline RV \% pred & Spearman & -0.431 & $<0.001$ & & \\
\hline $\mathrm{RV} / \mathrm{TLC} \%$ pred & Spearman & -0.340 & 0.006 & & \\
\hline MBNW $S_{\text {cond }} \times V_{T}$ & Spearman & -0.380 & 0.003 & & \\
\hline MBNW $S_{a c i n} \times V_{T}$ & Spearman & -0.250 & 0.056 & & \\
\hline $\mathrm{FEF}_{25-75 \%} \%$ pred & Pearson & 0.340 & 0.006 & & \\
\hline Alveolar $F_{\text {ENO }} \mathrm{ppb}$ & Spearman & -0.254 & 0.100 & & \\
\hline CT PRM-fSAD \% & Spearman & -0.051 & 0.717 & & \\
\hline $\begin{array}{l}\text { CT PRM inferior to superior } \\
\text { gradient } \Delta \mathrm{HU}\end{array}$ & Pearson & -0.197 & 0.152 & & \\
\hline
\end{tabular}

Data are presented as median (interquartile range), $\mathrm{n}(\%)$ or mean $\pm \mathrm{SD}$, unless otherwise stated. Ctrl: healthy controls; ComR: complete asthma remission subjects; ClinR: clinical asthma remission subjects; PersA: persistent asthma patients; FEV $_{1}$ : forced expiratory volume in $1 \mathrm{~s}$; $\mathrm{PC}_{20}$ : provocative concentration causing a $20 \%$ fall in $\mathrm{FEV}_{1}$; $\mathrm{FVC}$ : forced vital capacity; IOS: impulse oscillometry; $R_{20}$ : resistance at $20 \mathrm{~Hz}$; $R_{5}$ : resistance at $5 \mathrm{~Hz}$; $\mathrm{AX}$ : area of reactance; RV: residual volume; TLC: total lung capacity; MBNW: multiple-breath nitrogen washout; $\mathrm{S}_{\text {cond: }}$ conductive ventilation heterogeneity; $S_{\text {acin }}$ : acinar ventilation heterogeneity; $V_{T}$ : tidal volume; $\mathrm{FEF}_{25-75 \%}$ : forced expiratory flow at $25-75 \%$ of the pulmonary volume; $F_{\text {ENO }}$ : fraction of exhaled nitric oxide; CT PRM: computed tomography parametric response mapping; fSAD: functional small airways disease. ${ }^{\#}$ : data were log2-transformed to obtain normal distribution; ${ }^{~}: \mathrm{p}$-value based on Chi-squared test; ${ }^{+}: \mathrm{p}$-value based on ANOVA. 
Clinical characteristics and PExA mass in the subject groups were compared using independent sample t-test for normally distributed data (including log2-transformed variables), Mann-Whitney U-tests for non-normally distributed data and Fisher's exact tests for categorical variables. Likewise, PExA mass was correlated with small and large airway parameters using either Pearson or Spearman tests. Last, a stepwise multivariate regression analysis was performed to assess independent associations with PExA mass.

Clinical characteristics of the subject groups are presented in table 1 . ComR subjects were significantly younger than PersA subjects $(\mathrm{p}=0.027)$. The $\mathrm{FEV}_{1}$ was significantly higher in Ctrl and ComR compared to PersA subjects, and higher in ComR compared to ClinR subjects.

PExA mass was significantly lower in PersA compared to ComR and Ctrl subjects $(p=0.028$ and $p=0.003$, respectively) (figure 1). In addition, PExA mass was significantly lower in ClinR compared to Ctrl subjects $(\mathrm{p}=0.018)$. Comparison of particle size distribution per group did not yield additional information. This is the first study investigating exhaled particles in asthma remission subjects, showing a similar PExA mass in ComR compared to healthy controls and a decrease in PExA mass in ClinR compared to healthy controls, even though these individuals experience no wheeze or asthma attacks. Our findings are in concordance with the previously stated hypothesis that more SAD leads to decreased exhalation of particles. The fact that ClinR subjects exhale fewer particles suggests that these subjects still have ongoing SAD similar to persistent asthmatics. In contrast, ComR subjects exhale similar amounts of particles compared to healthy controls, possibly due to outgrown SAD. Next, we assessed the correlations between PExA mass and known small and large airway parameters. Results of these bivariate correlations are presented in table 1. Increased PExA mass was associated with less severe BHR and parameters of both large airway function (higher $\mathrm{FEV}_{1} \%$ pred and higher ratio of $\mathrm{FEV}_{1}$ to forced vital capacity (FVC)) and small airway function (higher forced expiratory flow at $25-75 \%$ of the pulmonary volume $\%$ pred, less hyperinflation as reflected by lower residual volume \% pred, lower IOS resistance at $5 \mathrm{~Hz}$ minus resistance at $20 \mathrm{~Hz}\left(R_{5}-R_{20}\right)$ and decreased MBNW conductive ventilation heterogeneity multiplied by tidal volume $\left.\left(\mathrm{S}_{\text {cond }} \times V_{\mathrm{T}}\right)\right)$. No correlation with PExA mass and PRM-defined (functional) small airways disease was observed. Finally, a stepwise multiple regression analysis was performed, including all variables significantly associated with PExA mass in the bivariate analysis (table 1). This analysis showed that MBNW $\mathrm{S}_{\text {cond }} \times V_{\mathrm{T}}$ was independently associated with PExA mass.

SOARES et al. [4] found a correlation between mean number of particles per exhalation and $\mathrm{FEV}_{1} / \mathrm{FVC}$ ratio $(\mathrm{R}=0.246, \mathrm{p}=0.021)$, and between surfactant $\mathrm{A}$ PExA concentration and $R_{5}-R_{20}(\mathrm{R}=0.257, \mathrm{p}<0.05)$. In accordance with these findings of SOAREs et al. [4], we show that increased PExA mass is associated with better function of both the large and the small airways.

In conclusion, PExA mass can distinguish asthmatics from healthy individuals. In addition, we show that subjects with complete, but not clinical, asthma remission exhale more PExA mass compared to asthma subjects. Our findings are in concordance with previous studies showing that decreased PExA mass is associated with more severe obstructive pulmonary disease [7, 14]. These results reinforce the theory that clinical asthma remission subjects still have ongoing SAD and that subjects in complete asthma remission have completely outgrown their disease [10]. Our observations demonstrate that higher PExA mass is not only related to better large airway function, but also independently associated with SAD as reflected by $\mathrm{S}_{\text {cond. }}$ This indicates that PExA mass could potentially be used as a tool to assess SAD. Future research

FIGURE 1 Particles in exhaled air (PExA) mass per subject group. Independent sample t-test $\mathrm{p}$-values are shown. Ctrl: healthy controls $(n=18)$; ComR: complete asthma remission subjects $(n=12)$; ClinR: clinical asthma remission subjects $(n=16) ;$ PersA: persistent asthma patients $(\mathrm{n}=18)$.

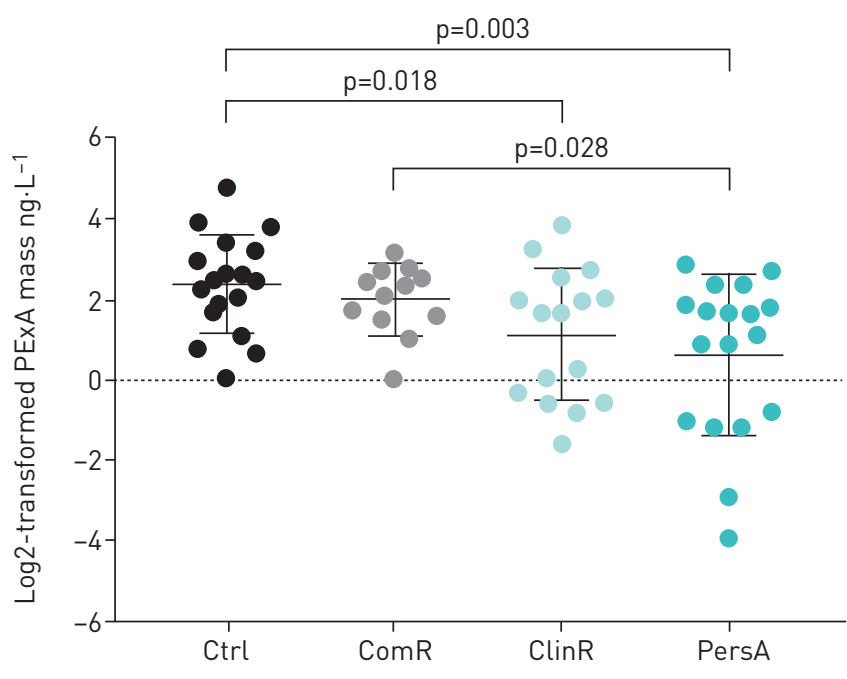


should focus on exploring the composition of exhaled particles to gain more insight into the pathophysiology of SAD in asthma persistence and remission.

Orestes A. Carpaij ${ }^{1,2}$, Susan Muiser ${ }^{1}$, Alex J. Bell ${ }^{3}$, Huib A.M. Kerstjens $\oplus^{1,2}$, Craig J. Galban ${ }^{4}$, Aleksa B. Fortuna ${ }^{4}$, Salman Siddiqui ${ }^{3}$, Anna-Carin Olin ${ }^{5}$, Martijn C. Nawijn ${ }^{1,6}$ and Maarten van den Berge ${ }^{1,2}$

${ }^{1}$ University of Groningen, University Medical Center Groningen, Dept of Pulmonology, Groningen, The Netherlands. ${ }^{2}$ University of Groningen, University Medical Center Groningen, Groningen Research Institute for Asthma and COPD, Groningen, The Netherlands. ${ }^{3}$ NIHR Biomedical Research Centre, Respiratory Theme and Dept of Respiratory Sciences, University of Leicester, Leicester, UK. ${ }^{4}$ University of Michigan, Dept of Radiology, Ann Arbor, MI, USA. ${ }^{5}$ Occupational and Environmental Medicine, Dept of Public Health and Community Medicine, Institute of Medicine, Sahlgrenska Academy, University of Gothenburg, Gothenburg, Sweden. ${ }^{6}$ University of Groningen, University Medical Center Groningen, Dept of Pathology and Medical Biology, Groningen, The Netherlands.

Correspondence: Orestes A. Carpaij, Dept of Pulmonology, University of Groningen, Hanzeplein 1, 9713 GZ Groningen, The Netherlands. E-mail: o.a.carpaij@umcg.nl

Received: 15 Aug 2019 | Accepted: 19 Aug 2019

Author contributions: O.A. Carpaij, S. Muiser, M. van den Berge and A-C. Olin interpreted the subjects' data and PExA results. O.A. Carpaij, S. Muiser and M. van den Berge were involved in drafting the manuscript. H.A.M. Kerstjens, M.C Nawijn, S. Siddiqui and A.J. Bell were involved in conception and design of the study, and interpretation of the data, and contributed to writing the manuscript. S. Siddiqui and A.J. Bell conducted the image analysis of the CT scans. All authors read and approved the final manuscript.

Conflict of interest: O.A. Carpaij has nothing to disclose. S. Muiser has nothing to disclose. A.J. Bell has nothing to disclose. H.A.M. Kerstjens reports an unrestricted research grant and fees for participation in advisory boards from GlaxoSmithKline (the sponsor of this study), as well as from Boehringer Ingelheim and Novartis. He also reports fees for advisory board participation from AstraZeneca and Chiesi, board membership fees from Almirall, and fees per patient for recruitment in trials from GlaxoSmithKline, Novartis and Fluidda. All the above were paid to his institution. C.J. Galban reports that Parametric Response Mapping, of which he is a coinventor, is licenced to Imbio, LLC, by the University of Michigan. A.B. Fortuna has nothing to disclose. S. Siddiqui reports grants from the Chiesi Onulus Foundation, Midlands Asthma and Allergy Research Association, the NIHR Biomedical Research Centre, the Sir Jules Thorne Trust and the Medical Research Council, and personal fees from Chiesi, GlaxoSmithKline, AstraZeneca, Novartis, Owlstone Medical, Napp, Mundipharma, Boehringer Ingelheim and ERT Medical, outside the submitted work. A-C. Olin reports that she has patent WO2009045163 (Collection and measurement of exhaled particles) issued and patent WO2013117747 1 (A device and method for non-invasive analysis of particles during medical ventilation) pending. M.C. Nawijn reports grants from GlaxoSmithKline Ltd and the Ministry of Economic Affairs and Climate Policy during the conduct of the study. M. van den Berge reports grants paid to his institution from GlaxoSmithKline, TEVA, AstraZeneca, Chiesi and Genentech, outside the submitted work.

Support statement: This project was sponsored by GlaxoSmithKline, supported by grants from the National Institute for Health Research (NIHR) Leicester (Biomedical Research Centre: Respiratory Theme; grant agreement number RM65G0113), and is co-financed by the Ministry of Economic Affairs and Climate Policy by means of the PPP Allowance made available by the Top Sector Life Sciences and Health to stimulate public-private partnerships. The views expressed are those of the authors and not necessarily those of the National Health Service, the NIHR or the Dept of Health. Funding information for this article has been deposited with the Crossref Funder Registry.

\section{References}

1 Lipworth B, Manoharan A, Anderson W. Unlocking the quiet zone: the small airway asthma phenotype. Lancet Respir Med 2014; 2: 497-506.

2 McNulty W, Usmani OS. Techniques of assessing small airways dysfunction. Eur Clin Respir J 2014; 1: 25898.

3 Postma DS, Brightling C, Baldi S, et al. Exploring the relevance and extent of small airways dysfunction in asthma (ATLANTIS): baseline data from a prospective cohort study. Lancet Respir Med 2019; 7: 402-416.

4 Soares M, Mirgorodskaya E, Koca H, et al. Particles in exhaled air (PExA): non-invasive phenotyping of small airways disease in adult asthma. J Breath Res 2018; 12: 046012.

5 Almstrand AC, Ljungström E, Lausmaa J, et al. Airway monitoring by collection and mass spectrometric analysis of exhaled particles. Anal Chem 2009; 81: 662-668.

6 Bake B, Larsson P, Ljungkvist G, et al. Exhaled particles and small airways. Respir Res 2019; 20: 8.

7 Larsson P, Lärstad M, Bake B, et al. Exhaled particles as markers of small airway inflammation in subjects with asthma. Clin Physiol Funct Imaging 2017; 37: 489-497.

8 Carpaij OA, Nieuwenhuis MAE, Koppelman GH, et al. Childhood factors associated with complete and clinical asthma remission at 25 and 49 years. Eur Respir J 2017; 49: 1601974.

9 Panhuysen CI, Vonk JM, Koëter GH, et al. Adult patients may outgrow their asthma: a 25-year follow-up study. Am J Respir Crit Care Med 1997; 155: 1267-1272.

10 Carpaij OA, Burgess JK, Kerstjens HAM, et al. A review on the pathophysiology of asthma remission. Pharmacol Ther 2019; 201: 8-24. 
11 Broekema M, Timens W, Vonk JM, et al. Persisting remodeling and less airway wall eosinophil activation in complete remission of asthma. Am J Respir Crit Care Med 2011; 183: 310-316.

12 Galbán CJ, Han MK, Boes JL, et al. Computed tomography-based biomarker provides unique signature for diagnosis of COPD phenotypes and disease progression. Nat Med 2012; 18: 1711-1715.

13 Bell AJ, Foy BH, Richardson M, et al. Functional CT imaging for identification of the spatial determinants of small-airways disease in adults with asthma. J Allergy Clin Immunol 2019; 144: 83-93.

14 Lärstad M, Almstrand AC, Larsson P, et al. Surfactant protein A in exhaled endogenous particles is decreased in chronic obstructive pulmonary disease (COPD) patients: a pilot study. PLoS One 2015; 10: e0144463. 